\title{
Multi-objective design of fuzzy logic controller in supply chain
}

\author{
Mahdi Ghane ${ }^{1}$ and Mohammad Jafar Tarokh ${ }^{2^{*}}$
}

\begin{abstract}
Unlike commonly used methods, in this paper, we have introduced a new approach for designing fuzzy controllers. In this approach, we have simultaneously optimized both objective functions of a supply chain over a two-dimensional space. Then, we have obtained a spectrum of optimized points, each of which represents a set of optimal parameters which can be chosen by the manager according to the importance of objective functions. Our used supply chain model is a member of inventory and order-based production control system family, a generalization of the periodic review which is termed 'Order-Up-To policy.' An auto rule maker, based on non-dominated sorting genetic algorithm-ll, has been applied to the experimental initial fuzzy rules. According to performance measurement, our results indicate the efficiency of the proposed approach.
\end{abstract}

Keywords: Supply chain, Fuzzy logic controller, Multi-objective optimization

\section{Background}

A supply chain is a system of organizations, people, technology, activities, information, and resources involved in performing the functions of procurement of raw materials, transformation of raw materials into intermediate and finished product that is delivered to the end customer. Recently, enterprises have exposed a growing interest in efficient supply chain management. This is due to the rising cost of manufacturing and transportation, the globalization of market economies, and the customer demand for diverse products of short life cycles. A properly designed supply chain system is essential for competitive performance. Control theory advocates a wide range of attributes and standard measures for proper design (Towill 1982). There are different methods to evaluate the performance of a supply chain especially in different case studies. Wang et al. (2007) evaluated the performance of a supply chain for mass customization.

Fundamentally, there are two common objective functions in supply chain systems (Wang et al. 2007): (1) inventory-level recovery and (2) attenuation of demand rate fluctuations on the ordering rate. Proper inventorylevel recovery results in lower inventory costs and better

\footnotetext{
* Correspondence: mjtarokh@kntu.ac.ir

${ }^{2}$ Industrial Engineering Department, K.N.Toosi University of Technology, Tehran 19697 64499, Iran

Full list of author information is available at the end of the article
}

customer services, although in order to optimize the system performance, the designer has to select fixed or variable stock values (agile production systems; Towill and McCullen 1999). The second objective function aims at the reduction of the 'bullwhip' effect. According to Lee et al. (1997), a small variation in the demands of the downstream end-customer may cause remarkable variation in the upstream supplier's side which is known as the bullwhip effect. The term bullwhip is not a new concept (Forrester 1961; Burbidge 1991; Figure 1).

Many researchers have worked on the bullwhip effect and its attenuation. Christer and Robert (2002) studied the complexities of bullwhip by using fuzzy numbers in the bullwhip models. Peter and Dennis (2002) verified how proven material flow control principles considerably reduce the bullwhip in a supply chain. Some researchers are dedicated to forecasting policy. The bullwhip problem is studied by exponential smoothing algorithms in both 'stand-alone' passing-on-orders mode and within inventory-controlled feedback systems in Dejonckheere et al. (2003). Also, Xiaolong (2004) derived and measured a forecasting procedure that minimizes the mean squared forecasting error for the specified demand process. Disney and Towill (2003) proposed a good analytical expression in the inventory position and pipeline position to quantify the bullwhip effect. Jiuh-Biing (2005) 


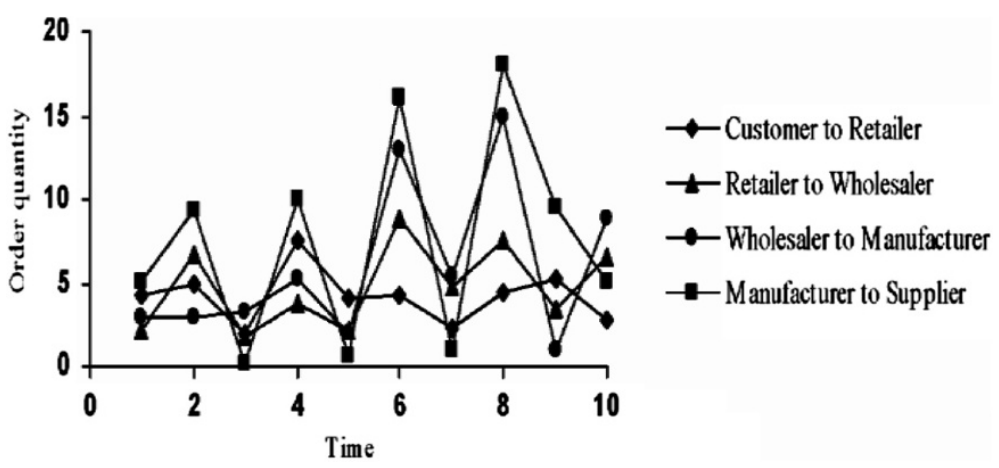

Figure 1 Increasing variability of orders up the supply chain. Adapted from Yu and Zhang (2010).

presented a multi-layer demand-responsive logistics control strategy for alleviating the bullwhip effect.

In the case of inventory-level recovery, the work of Disney and Towill (2003) can be mentioned which uses control theory method to evaluate this objective function in the general supply chain to cover the dynamic behavior of the chain. However, for a simplified system, we can make an analytical measure. Disney and Towill (2003) tried to show how $\mathrm{Ti}, \mathrm{Ta}$, and Tw change as the balance between inventory-carrying costs (first objective) and production on-costs (second objective) alters. The sum of objectives in a simplified supply chain model is defined in Equation 1. Their solution only returns a single set of parameters and cannot be extended to a general model; in addition, it is not able to add more constraints to the model. Moreover, it does not cover the dynamic effect of different demand signals.

$$
\text { Score }=\left(K \times V R_{\mathrm{ORATE}}\right)+V R_{\mathrm{AINV}}
$$

Achieving a well-designed supply chain (SC) is very difficult since various sources of uncertainty and complex interactions among various entities (suppliers, manufacturers, distributors, retailers) exist in the SC. Structured uncertainty and unstructured uncertainty are the two major uncertainties in each model. One of the best solutions to deal with uncertainty is fuzzy logic. In Wang and Shu (2005), fuzzy set theory was used to minimize SC holding cost.

A good attempt to optimize and design a supply chain using a multi-objective viewpoint is presented by Mahnadm et al. (2009). In their work, fuzzy logic is used to handle the uncertainty of different suppliers. Banerjee and Roy (2009) considered the application of the intuitionistic fuzzy optimization in the constrained multiobjective stochastic inventory model. Larbani (2009) surveyed most of the approaches for solving noncooperative fuzzy games in normal form. In addition, applications of these games were also discussed. Yu and Zhang (2010) proposed a generalized form of fuzzy game and extended as a cooperative fuzzy game. They also provided a practical application for production problem. Chen et al. (2010) formulated a game framework for the strategic behavior of supply chain partners based on fuzzy multi-objective programming, but fuzzy rules mostly were fixed and defined by expert knowledge. Due to the lack of an intelligent mechanism to derive fuzzy rules, fuzzy membership functions based on different weights between objective functions were clear in these attempts.

In this study, a multi-objective approach is used to optimize fuzzy controllers and forecasting policy simultaneously. Structured uncertainty is one of the main challenges in a well-designed supply chain. In this regard, we use a fuzzy logic controller in inventory policy and work in process policy.

The paper is organized as follows: simulation results are presented in the 'Results and discussion' section; concluding remarks and suggestions for future research directions, in the 'Conclusions' section. This paper ends with the 'Methods' section which offers a review on basic theory of the suggested method.

\section{IOBPCS model description}

The first attempts for modeling and controlling decentralized systems were done by Forrester (1961). The objective of this work was to perform a dynamic analysis, simulation of industrial systems using discrete dynamic mass balances, and linear and non-linear delays in the distribution channels and manufacturing sites. Various alternative methods have been proposed for modeling supply chains which are classified into four groups (Beamon 1998; Balan et al. 2007).

A simple decentralized supply chain is shown in Figure 2.

For modeling each echelon of this supply chain, a powerful generic order-based production control system (IOBPCS) model was presented by Towill (1982) in a block diagram form (Figure 3).

The IOBPCS family has been considered in both continuous and discrete time using the Laplace and z-transform (Chen et al. 2010; Deb 2001). Via specific parameter settings, a range of well-known replenishment algorithms 


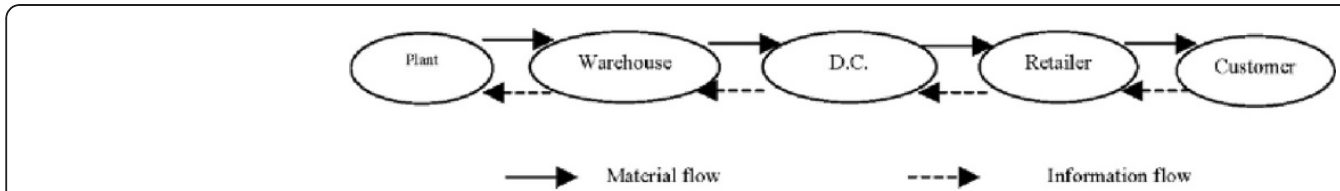

Figure 2 A simple supply chain model. Adapted from Yu and Zhang (2010).

could be implemented. The IOBPCS family consists of a range of PIC systems with five main components:

- Demand policy

- Lead-time

- Inventory policy (inventory feedback loop)

- Pipeline policy (work in progress (WIP) feedback loop)

- Target stock setting.

The demand policy is a feed-forward loop, which, in essence, is a forecasting mechanism that averages the current market demand to reach smoother orders placed on a supplier. The more accurate this forecast, the fewer inventories will be required in the supply chain (Hosoda and Disney 2005). The lead time simply represents the time between placing an order and receiving the goods into inventory. The inventory policy, which is a feedback loop, is an error-compensating mechanism based on the inventory or net stock levels. The pipeline policy, which is a feedback loop, determines the rate at which work in process (WIP) deficit between desired WIP level and actual WIP level is recovered.

As is common practice in the design of engineering systems, and assuming that lead times are not too long, we have incorporated a proportional controller which, in this paper, is triggered by multi-objective optimization into the inventory feedback loop to shape its dynamic response. The target stock setting can be either fixed or a multiple of current average sale rates. Standard nomenclature used in industrial dynamics is adopted to stand for input, output, and intermediate signals in the block diagram (Haralambos et al. 2008):

- AINV: actual inventory holding

- AVCON: average consumption

- AWIP: actual WIP holding

- COMRATE: completion rate

- CONS: consumption or market demand

- DINV: desired inventory level

- DWIP: desired WIP

- EINV: error in inventory holding

- EWIP: error in WIP

- ORATE: order rate

Recently, researchers have studied different properties of the so-called inventory order-based production control system (IOBPCS) model. As a case in point, the stability of the discrete-time IOBPCS model has been investigated by Disney and Towill $(2003,2005)$ : they presented a general methodology to derive the critical stability boundary using a transfer function.

\section{Fuzzy rule base optimization}

We used a fuzzy logic controller (FLC) in inventory policy and work in process policy. The FLC has two inputs (premises): error, $\mathrm{e}(\mathrm{t})$, and error derivative, $\mathrm{de}(\mathrm{t})$, and

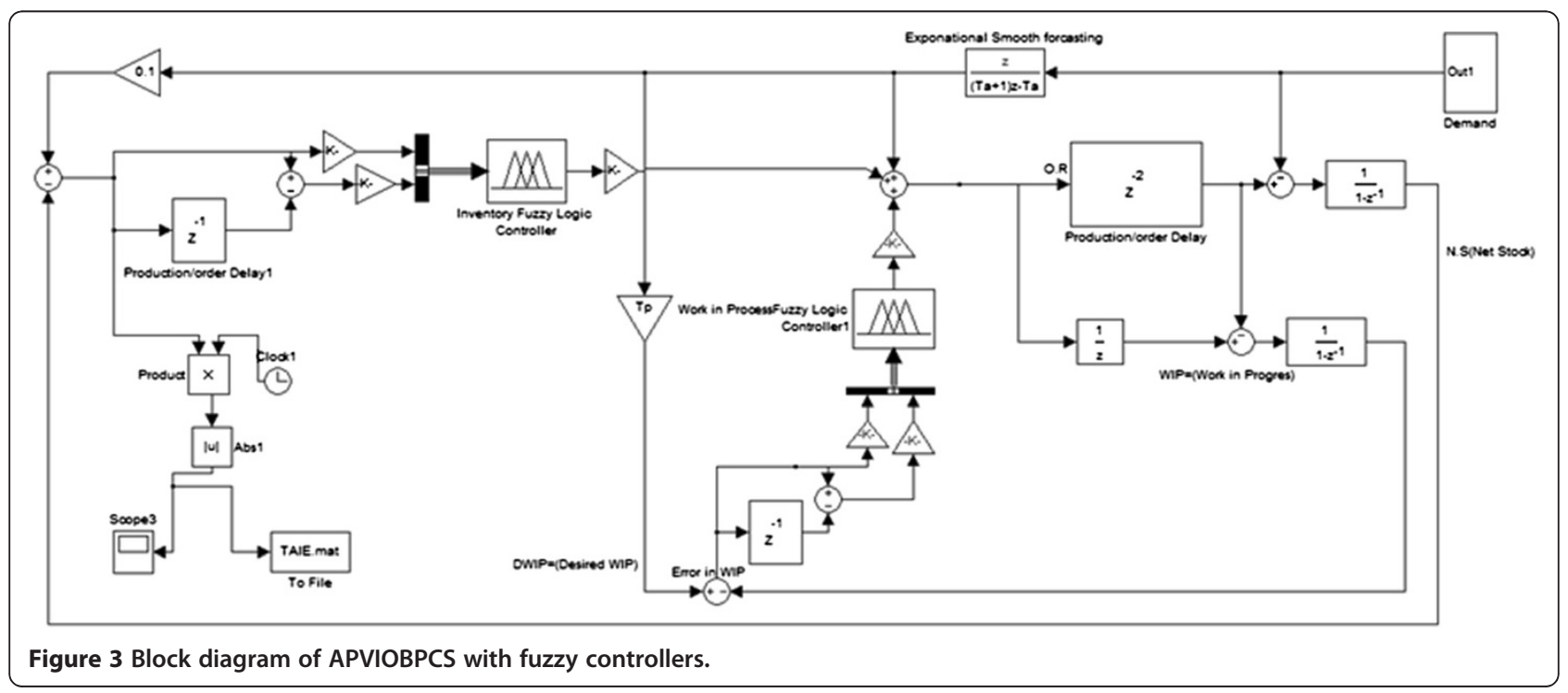


one output (consequent): control action, $\mathrm{u}(\mathrm{t})$. Each of these three controller variables is evaluated over a normalized space range of $[-1,1]$, using five membership functions (NB, NS, Z, PS, PB). The Mamdani interference method and the AND connective are utilized with equal rule weighting. Then, a rule base consisting of 25 rules is produced.

One approach could be to optimize the rule base using all possible combinations of premise/consequent possibilities. We, therefore, have to test 450 different rules to achieve the best set of rules, which is time-consuming. Another alternative method is to diminish the rules. In this respect, there are different rule decreasing methods (Foran 2002). Before applying the method described in Foran (2002), some assumptions should be considered which are essentially based on experience.

The magnitude of the output control action is consistent with the magnitude of the input value; in other words, an extreme input value (premise) results in an extreme output value (consequent), a mid-range input value causes a midrange output value, and a small/zero input value is synonymous with a small/zero output value.

If a large negative (positive) input generates a large negative (positive) response, then it is likely that smaller negative (positive) inputs will demand a response with the same polarity, but it would be with a smaller magnitude, and so on until a zero-crossing point is reached at the point whose response polarity changes.

The above-mentioned approach is a variation of the method used in Ross (1995). The consequent rule space is then 'overlaid' upon the premise coordinate system and is partitioned into regions where each region represents a consequent fuzzy set. The rule base is then extracted by determining the consequent region in which each premise combination point lies. Different possible consequent space partitions are defined using two parameters: consequentline angle, $\theta$, and consequent-region spacing, Cs.

The consequent-line angle defines the slope of the consequent line, which is used to create the space partitions. Cs is a proportion of the fixed distance between premises on the coordinate system and is used to define the distance between consequent points along the consequent line defined by angle $\theta$.

This method is illustrated in Figure 4, considering $\theta=50^{\circ}$ and $\mathrm{Cs}=1$ with fixed premise spacing which is equal to consequent spacing. It should be noted that this may not be a real rule base in our study and it is just used to show the method.

\section{Results and discussion} Structure description

In this part, we are going to present the results of our simulation to reflect the efficiency and the flexibility of our proposed method in finding optimal fuzzy controller

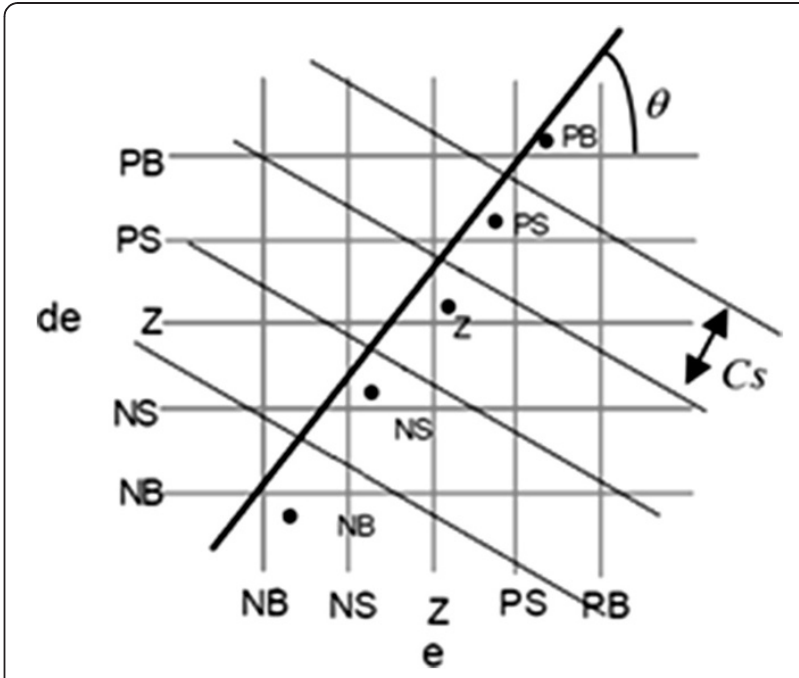

Figure 4 Fuzzy logic rule optimizer space.

parameters. We will use a discrete model of the most general member of the IOBPCS family, the automatic pipeline inventory and the order-based production control system (APVIOBPCS).

Figure 5 illustrates a block diagram of our proposed structure. Inputs of the multi-objective optimizer block are system objective functions. Notwithstanding the fact that this is a general structure, in our study, objective functions are inventory recovery response and attenuating bullwhip. According to these objective functions, and using the non-dominated sorting genetic algorithmII (NSGA-II) method as an algorithm for multi-objective optimization, two sets of optimal parameters are produced. The first set directly affects the system dynamics, and the other set is used as the fuzzy tuning block input to optimize rule base and scaling gains. Outputs of multi-objective optimizer block and boundaries are shown in Table 1.

For evaluating objective functions, bullwhip is quantified as the ratio of output variance (ORATE) to the variance of input (Demand) while white noise represents

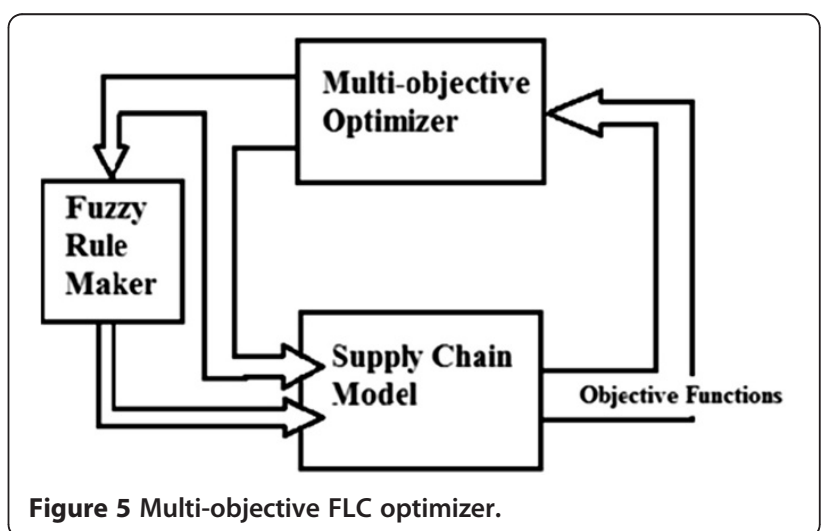


Table 1 Fuzzy controller parameters and boundaries

\begin{tabular}{|c|c|c|c|c|}
\hline & & Parameters & Boundaries & Sample \\
\hline \multirow[t]{5}{*}{ Inventory policy } & FLC & $\theta$ inv & {$[5,170]$} & 79.53 \\
\hline & & Cs_inv & {$[0.5,2]$} & 1.346 \\
\hline & Scaling gain & G1_e & {$[0.5,3]$} & 0.9282 \\
\hline & & G1_de & {$[0.5,3]$} & 0.7175 \\
\hline & & G1_out & {$[-2,2]$} & 1.0013 \\
\hline \multirow[t]{5}{*}{ Work in process policy } & FLC & $\theta$ _wip & {$[5,170]$} & 17.496 \\
\hline & & Cs_wip & {$[0.5,2]$} & 0.9529 \\
\hline & Scaling gain & G2_e & {$[0.5,3]$} & 1.1328 \\
\hline & & G2_de & {$[0.5,3]$} & 0.7797 \\
\hline & & G2_out & {$[-2,2]$} & 0.9529 \\
\hline Forecasting & & $\mathrm{Ta}$ & {$[1,10]$} & 2.578 \\
\hline
\end{tabular}

random demand in the market place, and the metric for quantifying inventory recovery responsiveness is the integral of time multiplied by absolute error (ITAE) which is defined by Equation 2 (Disney and Towill 2003):

$$
\operatorname{ITAE}_{\mathrm{AINV}}=\sum_{n=0}^{\infty} n|E|
$$

This error is the difference between desired inventory and actual inventory. Also, the desired inventory level may be fixed or be a multiple of average order.

\section{Results and comparisons}

As we mentioned, NSGA-II is used inside the multiobjective optimizer block. In this study, we fix the population of NSGA-II to 165 individuals. The optimal Pareto front, obtained through the multi-objective optimization of the parameters, is presented in Figure 6.

Figure 6 compares the fuzzy controller with the paction controller. In some area, the fuzzy controller acts better than the p-action controller, and in some area, it does not. The major feature of fuzzy controllers is their ability in dealing with uncertainty, which is discussed in the subsequent part; nevertheless, in this study, we decrease the number of rules and use only 165 individuals in our simulation. Probably, it could be more optimal if a different setting is used for multi-objective block.

\section{Uncertainty analysis}

P-action controller is compared with fuzzy controller in the case of structured uncertainty. These may happen in inventory policy or forecasting policy. Exponential smoothing forecasting is used with the parameter Ta, which is shown in Figure 3. Lead time (Tp) is the parameter of forecasting policy which plays a crucial role because it defines the order of the system. A sample is selected from the Pareto front. Optimized parameters and their boundaries are shown in Table 1 for fuzzy controller, and p-action controller parameters are shown in Table 2.

Rule bases which resulted from our method for inventory loop and work in process loop are presented in Figures 7 and 8 , respectively.

The order quantity of the system is presented for these controllers in normal situation in Figure 9. Normal parameters are shown in Tables 1 and 2. Now, we assume that there is some structured uncertainty in both forecasting mechanism and lead time. Hence, we assume $\mathrm{Tp}=1.5$ and $\mathrm{Ta}=3$ instead of $\mathrm{Tp}=1$ and $\mathrm{Ta}=1.7213$. The response is shown in Figure 10.

Although $\mathrm{Ta}$ is an important parameter in forecasting mechanism, uncertainty in $\mathrm{Tp}$ as lead time is more important because it defines the order of the system. It is clear that fuzzy controller acts much better than paction controller.

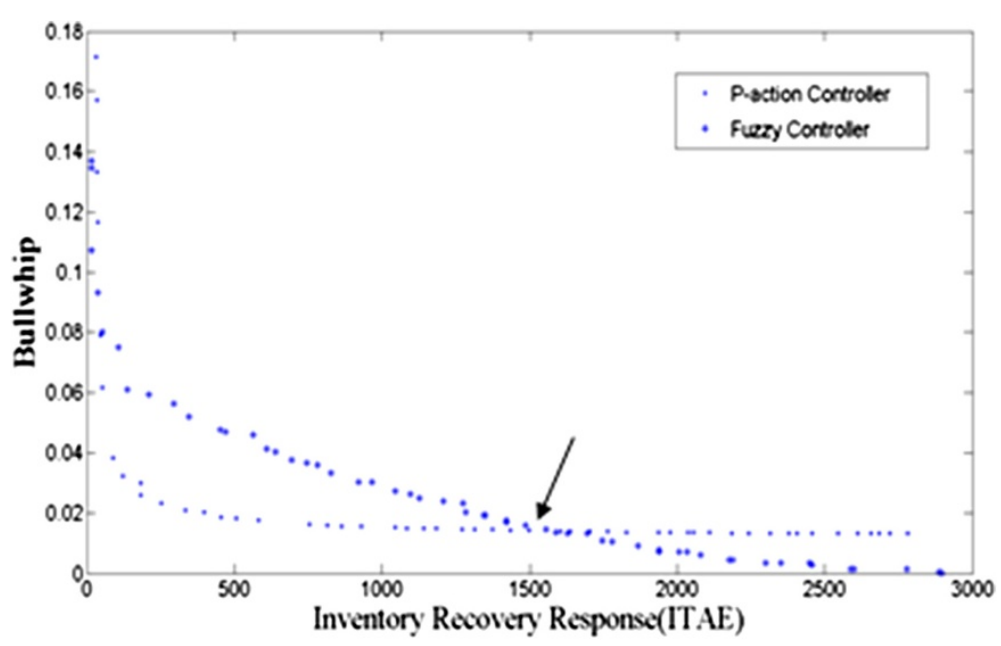

Figure 6 Pareto optimal front. The arrow refers to a set of parameters which are presented in the subsequent part. 
Table $2 \mathrm{P}$-action controller parameters and boundaries

\begin{tabular}{ccc}
\hline & Parameters & Sample \\
\hline P-action & $\mathrm{Ti}$ & 7.9353 \\
& $\mathrm{Ta}$ & 1.7213 \\
$\mathrm{TW}$ & 2.2507 \\
\hline
\end{tabular}

\section{Conclusions}

In supply chain, control parameter settings for different policies and different cases are very important. It is more critical when we face uncertainty. In this study, based on a fuzzy controller, the bi-objective supply chain model has been analyzed. In this manner, a rule base-maker algorithm has been used to make new fuzzy rule bases to achieve the optimum rule base. Using a multi-objective manner based on NSGA-II, the optimum parameters for rule maker's input and scaling and forecasting gains have been obtained, and then they have been used for an optimum design of fuzzy controller. In case of the presence of uncertainty, both p-action and fuzzy controllers have been compared, and the obtained results indicate excellent robustness in designed fuzzy controller compared to $\mathrm{p}$-action controller. This robustness becomes more important when we face uncertain lead time because it changes system dynamic (the order of the system). This new bi-objective approach for supply chain design has been proposed which, in the case of uncertainty, is more robust than formerly used p-action controllers.

The results also show that combination of fuzzy logic and other soft computing methods is a good candidate for future development work because of its non-linear approximation capability and adaptability. Further perspective and attractive challenges for future research are the modification of different membership functions and the establishment of a non-linear-based modeling approach for real supply chain, e.g., the improvement of forecasting mechanism due to its fundamental effect on bullwhip.

\section{Methods}

NSGA-II implementation for multi-objective optimization Multi-objective optimization (MOO) methods are utilized when two or more objective functions are

\begin{tabular}{|c|c|c|c|c|c|}
\hline de/e & NB & NS & Z & PS & PB \\
\hline NB & NB & NB & NS & NS & Z \\
\hline NS & NS & NS & NS & Z & Z \\
\hline Z & NS & $Z$ & Z & Z & PS \\
\hline PS & Z & Z & PB & PS & PS \\
\hline PB & Z & PS & PB & PB & PB \\
\hline
\end{tabular}

Figure 7 Rule base for inventory loop.

\begin{tabular}{|c|c|c|c|c|c|}
\hline de/e & NB & NS & Z & PS & PB \\
\hline NB & NB & NB & NS & Z & PS \\
\hline NS & NB & NS & Z & PS & PB \\
\hline Z & NB & NS & Z & PS & PB \\
\hline PS & NB & NS & Z & PS & PB \\
\hline PB & NS & Z & PS & PB & PB \\
\hline
\end{tabular}

Figure 8 Rule base for work in process loop.

necessary to be optimized simultaneously (Deb 2001). In the case of $\mathrm{MOO}$ methods, relative importance of objective functions is not generally known until the system's best capabilities are determined and trade-off between the objective functions is fully understood. This feature is the main advantage of MOO methods in comparison with simply weighted cost functions. The definition of an MOO problem requires substantial acquaintance with some preliminary definitions which are described as follows:

Objective functions: some functions of decision variables and criteria for estimating the appropriateness of a response. There are numbers of $k \geq 2$ objective functions in MOO which are shown as the vector $f(\bar{x})=$ $\left[f_{1}(\bar{x}), \ldots, f_{k}(\bar{x})\right]$.

Decision variables: a set of variables whose values suggest the response the response and can be right or wrong. These variables are presented in a form of $\bar{x}=$ $\left[x_{1}, x_{2}, \ldots, x_{r}\right]^{T}$ where $r$ is the number of variables.

- Constraints: defined in a form of some functions of decision variables, such as equalities or inequalities:

Equality $: g_{i}(\bar{x})=0 ; i=1, \ldots, p$,
Inequality $: h_{i}(\bar{x}) \leq 0 ; i=1, \ldots, m$.

- Feasible region: it is defined as the set of whole decision variables satisfying all constraints.

- Dominancy: NSGA-II is used in non-dominated sorting for fitness assignments. All individuals not dominated by any other individuals are assigned front number 1 . All individuals only dominated by individuals in front number 1 are assigned front number 2, and so on. Selection is made using tournament between two individuals. The individual with the lowest front number is selected if the two individuals are from different fronts. The individual with the highest crowding distance is selected if they are from the same front. 


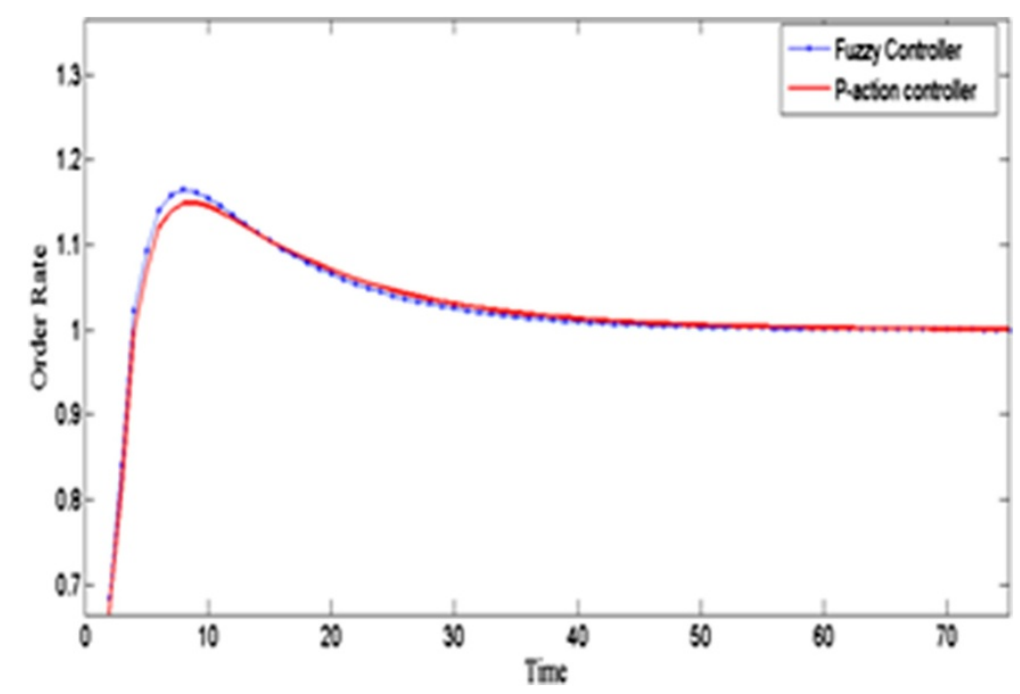

Figure 9 Order rate placed on a supplier.

In other words, the decision vector $\bar{x}_{2} \in F$ is dominated by the decision vector $\bar{x}_{1} \in F$, if and only if the decision vector $\bar{x}_{1}$ is better than or equal to $\bar{x}_{2}$ in all objectives:

$$
\bar{x}_{1} \succ \bar{x}_{2} \leftrightarrow f\left(\bar{x}_{1}\right) \leq f\left(\bar{x}_{2}\right)
$$

Pareto: when the cost functions have no confliction with each other, in MOO problems, it is possible to come across a unit optimal response which optimizes the whole cost functions. Otherwise, it is not feasible to find a response which optimizes all cost functions. In fact, since $F(x)$ is a vector, any other components of $F(x)$ are competing with each other and there is no unique solution for this problem. If $\bar{x}_{2} \in F$ does not exist to dominate $\bar{x}_{1} \in F$, the decision vector $\bar{x}_{1}$ is called an optimal Pareto response. The set of optimal Pareto responses is also known as a Pareto optimal front. All solutions on the Pareto optimal front are optimal.

In fact, according to Equation 5, the aim of MOO is to find the optimal Pareto front in which every response minimizes at least one of the two or more objective functions. In other cases, we have to revise Equation 1. For example, if we want both objective functions be maximized, Equation 5 must be rewritten as

$$
\bar{x}_{1} \succ \bar{x}_{2} \leftrightarrow f\left(\bar{x}_{1}\right) \geq f\left(\bar{x}_{2}\right) .
$$

Now, MOO is defined as follows: Finding vector $\bar{x}^{*}=$ $\left[x_{1}{ }^{*}, x_{2}{ }^{*}, \ldots, x_{r}{ }^{*}\right]^{T}$ in a way that $p$ equality constraints (Equation 3 ) and $m$ inequality constraints (Equation 4 )

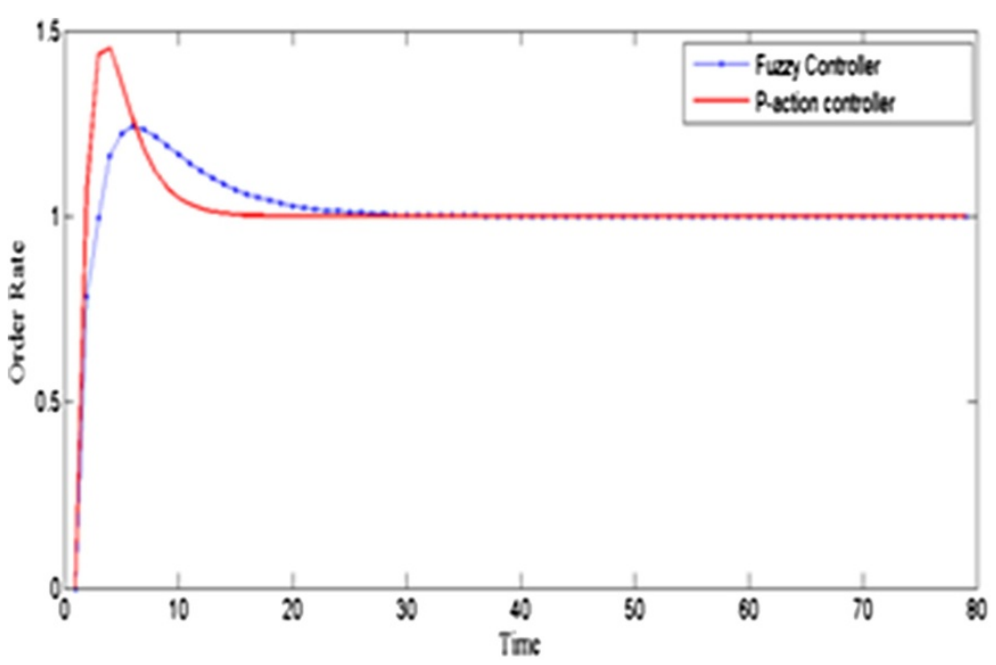

Figure 10 Order rate placed on a supplier with uncertainty. 
would be satisfied; likewise, the function vector $f(\bar{x})=$ $\left[f_{1}(\bar{x}), \ldots, f_{k}(\bar{x})\right]$ is optimized. In other words, we estimate a specific $\bar{x}^{*}$ in a feasible region which leads to an optimal amount for the whole amount of $k$ in the cost function.

In this article, in order to solve the available MOO problem, MATLAB software is utilized.

\section{Competing interests}

Both authors declare that they have no competing interest.

\section{Authors' contributions}

The work presented here was carried out as a collaboration between MJT and MG. Both authors read and approved the final manuscript.

\section{Authors' information}

Dr. MJT is an assistant professor in the Industrial Engineering Department a K.N.Toosi University of Technology, Tehran, Iran. Mr. MG is a faculty at Eqbal Lahouri Institute for Higher Education, Mashad, Iran.

\section{Acknowledgments}

The authors would like to thank Dr. Mahdi Aliyari, Dr. Hamid Khaloozadeh, and Dr. Mehrdad Kazerooni for their insightful comments and constructive suggestions that have improved the paper.

\section{Author details}

${ }^{1}$ Mechatronics Department, K.N.Toosi University of Technology, Tehran 19697 64499, Iran. ${ }^{2}$ Industrial Engineering Department, K.N.Toosi University of Technology, Tehran 19697 64499, Iran.

Received: 1 December 2010 Accepted: 3 March 2012

Published: 7 August 2012

\section{References}

Balan S, Prem V, Pradeep K (2007) Reducing the Bullwhip effect in a supply chain with fuzzy logic approach. Int J Integrated Supply Management 3:3

Banerjee S, Roy TK (2009) Application of the intuitionistic fuzzy optimization in the constrained multi-objective stochastic inventory model. J Tech 41:83-98

Beamon BM (1998) Supply chain design and analysis: models and methods. International Journal of Production Economics 55:281-294

Burbidge JL (1991) Period Batch Control (PBC) with GT—the way forward from MRP. In: Paper presented at the 26th BPICS annual conference, Birmingham, 14-16 November 1991

Chen Y-W, Larbani M, Liu C-H (2010) Simulation of a supply chain game with multiple fuzzy goals. Fuzzy Set Syst 161:1489-1510

Christer C, Robert F (2002) A position paper on the agenda for soft decision analysis. Fuzzy Set Syst 131:3-11

Deb K (2001) Multi-objective optimization using evolutionary algorithms. Wiley, Chichester

Dejonckheere J, Disney SM, Towill DR (2003) Measuring and avoiding the Bullwhip effect: a control theoretic approach. European Journal of Operational Research 147:567-590

Disney SM, Towill DR (2003) On the Bullwhip and inventory variance produced by an ordering policy. Omega 31:157-167

Disney SM, Towill DR (2005) Eliminating inventory drift in supply chains International Journal of Production Economics 331-344:93-94

Foran J (2002) Fuzzy controller optimisation using genetic algorithms. M. Eng Dissertation, School of Electronic Engineering, DCU

Forrester JW (1961) Industrial dynamics. MIT, Cambridge

Haralambos S, Panagiotis P, Tarantilis CD, Kiranoudis CT (2008) Dynamic modeling and control of supply chain systems: a review. Computers \& Operations Research 35:3530-3561

Hosoda T, Disney SM (2005) On variance amplification in a three echelon supply chain with minimum mean squared error forecasting. Omega: The International Journal of Management Science 34:344-358

Jiuh-Biing S (2005) A multi-layer demand-responsive logistics control methodology for alleviating the Bullwhip effect of supply chains. European Journal of Operations Research 161:797-811

Larbani M (2009) Non cooperative fuzzy games in normal form: a survey. Fuzzy Set Syst 160:3184-3210
Lee HL, Padmanabhan V, Whang S (1997) The bullwhip effect in supply chains. Sloan Management Review Spring 38:93-102

Mahnadm M, Yadollahpour MR, Famil-Dardashti V, Reza Hejazi S (2009) Supply chain modeling in uncertain environment with bi-objective approach Computers \& Industrial Engineering 56:1535-1544

Peter MC, Denis T (2002) Diagnosis and reduction of Bullwhip in supply chains. Supply Chain Management: An International Journal 7:64-179

Ross TM (1995) Fuzzy logic with engineering applications. McGraw-Hill, New York

Towill DR (1982) Dynamic analysis of an inventory and order based production control system. International Journal of Production Research 20:671-687

Towill DR, McCullen P (1999) The impact of agile manufacturing program on supply chain dynamics. International Journal of Logistics Management 10 (1):83-96

Wang J, Shu YF (2005) Fuzzy decision modeling for supply chain management. Fuzzy Set Syst 150:107-127

Wang Z, Qi G, Gu X, Pan X (2007) Supply chain performance evaluation system for mass customization. International Journal of Zhejiang University, Eng Sci 41(9):1567-1571

Xiaolong Z (2004) The impact of forecasting methods on the Bullwhip effect. Int $J$ Production Economics 88:15-27

Yu X, Zhang Q (2010) An extension of cooperative fuzzy games. Fuzzy Set Syst 161:1614-1634

doi:10.1186/2251-712X-8-10

Cite this article as: Tarokh and Ghane: Multi-objective design of fuzzy

logic controller in supply chain. Journal of Industrial Engineering International 2012 8:10

\section{Submit your manuscript to a SpringerOpen ${ }^{\circ}$ journal and benefit from:}

- Convenient online submission

- Rigorous peer review

- Immediate publication on acceptance

- Open access: articles freely available online

- High visibility within the field

- Retaining the copyright to your article

Submit your next manuscript at $\gg$ springeropen.com 